\title{
Coastal Flooding, Uncertainty and Climate Change: Science as a Solution to (mis) Perceptions? A Qualitative Enquiry in Three Coastal European Settings
}

\author{
Jean-Paul Vanderlinden ${ }^{\dagger *}$, Juan Baztan ${ }^{\dagger}$, Nabil Touili ${ }^{\dagger}$, Idrissa Oumar Kane ${ }^{\dagger}$, Bénédicte Rulleau ${ }^{\dagger}$, \\ Pedro Diaz Simal ${ }^{\ddagger}$, Luca Pietrantoni ${ }^{\dagger \dagger}$, Gabrielle Prati ${ }^{\dagger \dagger}$, and Fabio Zagonari ${ }^{\dagger \dagger}$
}

${ }^{\dagger}$ CEARC

Université de Versailles Saint-Quentin-en Yvelines

Guyancourt, France

${ }^{\dagger}$ Alma Mater Studorum

Universita di Bologna

Bologna, Italy

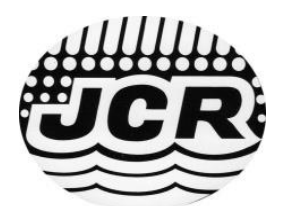

www.JCRonline.org
*Universidad de Cantabria

Santander, Spain

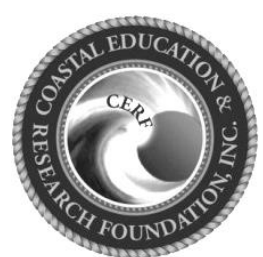

www.cerf-jcr.org

\begin{abstract}
Vanderlinden, J.-P.; Baztan, J.; Touili, N.; Kane, I.O.; Rulleau, B.; Diaz Simal, P.; Pietrantoni, L.; Prati, G., and Zagonari, F., 2017. Coastal flooding, uncertainty and climate change: Science as a solution to (mis) perceptions? A qualitative enquiry in three coastal European settings. In: Martinez, M.L.; Taramelli, A., and Silva, R. (eds.), Coastal Resilience: Exploring the Many Challenges from Different Viewpoints. Journal of Coastal Research, Special Issue No. 77, pp. 127-133. Coconut Creek (Florida), ISSN 0749-0208.

This paper contributes to the understanding of the interface between risk perception and climate change risk mitigation in coastal areas. In particular, we analyse the role of science-based knowledge and the so called "knowledge gap" in coastal stakeholders' verbalized perceptions of coastal risk. We use a qualitative approach to analyse of a corpus of 29 interviews conducted in three coastal European settings: Santander Bay (Spain), the Gironde Estuary (France), and Cesenatico (Italy). This analysis of stakeholders' perceptions of flood risk shows: (i) the science-based understanding of flooding as a probabilistic process is not always present and has little impact on the stated perceptions; and (ii) stakeholders and society as a whole frame risk mostly through values and norms. Given these findings, an increase in science-based knowledge within the world of coastal risk governance under climate change would contribute to safer coasts, provided that the production of science-based knowledge takes into account stakeholder values through a proactive dialogue with stakeholders.
\end{abstract}

ADDITIONAL INDEX WORDS: Coastal risk, coastal adaptation, social representation, coastal defense, risk perception.

\section{INTRODUCTION}

This paper contributes to the vibrant debate situated at a juncture within risk management, the intersection of disaster risk reduction, vulnerability analysis and climate change adaptation. It does so by proposing a framework to qualitatively analyze flood risk perception and tests this framework in three coastal European settings.

Flooding events during the last decade associated with extreme meteorological and/or tidal conditions (e.g., Hurricane Katrina, the Xynthia storm) indicate that human populations, in spite of scientific and technological progress, remain overexposed to coastal flood risk. The resulting debate is complexified by the need to consider the multidimensional impacts of climate change on coastal areas. Damages and losses associated with coastal floods have led to many analyses dealing with overexposure to flood risk, its consequences, associated poor governance principles (Eisenman et al., 2007), and an apparently poor

DOI: 10.2112/SI77-013.1 received 19 June 2015; accepted in revision 8 June 2016.

*Corresponding author: jean-paul.vanderlinden@uvsq.fr

${ }^{\circledR}$ Coastal Education and Research Foundation, Inc. 2017 understanding of the causes and consequences of floods at the policy level (e.g., Burby, 2006; Schneider, 2005).

Envisioning foresight dynamics and future exposure, the question is made even more complex by the uncertainties associated with climatic change (e.g., Cowell et al., 2006). One of the proposed solutions is to reinforce the science-policy interface in order to address what is understood as a knowledge gap leading to poorly designed flood risk management strategies (Zanuttigh, 2011).

In 2015, Rufat et al. conducted a review of 67 articles containing empirical studies of social vulnerability to flooding. They identify "risk perception" as a category of theoretical drivers of vulnerability. This category contains five elements, three of which are connected to knowledge, the fourth is "denial or acceptance" and the last one is "trust in officials." Their results indicate that most often proxies of previous experiences of floods are used in connection with awareness and associated (theoretical) preparedness. They identify contradictory results across various case studies. These contradictions call for finer qualitative analysis, such as the one presented in this paper.

In this study, we do not assume perceptions are essentially determined by knowledge. Rather, we operationalize the 
integrative approach to risk perception proposed by Renn (2008). This approach acknowledges that perceptions are shaped by personal and collective experiences at all scales. These experiences shape knowledge and associated worldviews and understandings of causal relationships, material constraints and associated salience criteria, as well as cultural norms and associated values. Scientific knowledge is thus just one of the potential influences on risk perception.

In the research presented here, we adopt the following working hypothesis: risk perceptions can lead to an underestimation of either the probability or consequences (or both) of a risk situation, which contributes to the persistence of areas with current and forecasted overexposure to coastal flood risk.

\section{Flood Risk Perception}

Three scientific communities are currently converging: the global/climate change analysis community, the disaster risk reduction community and the social vulnerability community (Birkmann, 2007; Birkmann et al., 2013). The treatment of risk perceptions, while referring to the common corpus of risk studies, differs slightly in terms of focus.

Within the climate change analysis community, perception analysis is focused mostly on the perception of climate change and its attribution. The focus centers on the perceptions of the determinants of climate change perception (e.g., Kahan et al., 2012; Lee et al., 2015; Leiserowitz, 2006; Lujala, Lein, and Rod, 2015) and on the need for climate change awareness in order to sustain mitigation and adaptation actions (Hansen, Sato, and Ruedy, 2012; Semenza et al., 2008).

Within the disaster risk reduction community, risk perception analysis is essentially centerd on the analysis of dissonance between expert evaluation and layperson assessment of risk situations (e.g., Siegrist and Gutscher, 2006) and on how experiencing past events impacts current behaviors (e.g., Witmarsh, 2008). Within this community, the analysis of perception is seen as a necessity in light of an observed shift toward non-structural approaches to disaster risk reduction (e.g., Adelekan and Asiyanbi, 2016).

Within the social vulnerability analysis community, "traditional" (see below) determinants of risk perception are identified as factors of vulnerability: access to information, knowledge, past experiences, beliefs, and customs (Cutter, Boruff, and Shirley, 2003; Cutter, Mitchell, and Scott, 2000). Such an understanding leads Rufat et al. (2015) to explicitly identify risk perception as a central thematic area in terms of indicators of social vulnerability.

Although the determinants of risk perception have long been identified and analyzed (Slovic, 1987; 1992), the associated results in their prescriptive dimensions have shown poor operational success at correcting overexposure. When trying to address overexposure, knowledge gaps have often been identified as a potential source of "misperception". This has led to an emphasis on the need to better communicate science-based findings to the lay public and/or policy makers. Nevertheless, these approaches have not been successful in changing the attitude of the public toward risky behavior.

More recently, integrative approaches to the analysis of risk perception have been proposed (Renn, 2008), stressing the fact that risk perceptions are determined by collective and personal manifestations of cultural backgrounds, socio-political institutions, cognitive affective factors and heuristics for information processing. This diversity of potential influences on (mis) perception indicates how ludicrous it is to try to address only one of these components in order to modify attitudes. Yet, the product of these factors can be assessed when analyzing the claims made by individuals when they are discussing their perceived exposure to risk. These claims fall into three categories (Renn, 2008): relevance, evidence and norms. Relevance claims express what matters to society and identify the important phenomena that should receive attention. Evidence claims express causal linkages. They are influenced by knowledge and are potentially associated with a need for science-based information. Their nature and the importance given to them are central if one wants to assess the role of science-based knowledge in perceiving risk. Finally, normative claims express what is good, tolerable, and/or acceptable. These three claim categories may be intertwined to produce one's attitude toward specific risks and to produce the discourse from which one's perceptions may be inferred through rigorous interview and analysis processes.

This paper engages in one such qualitative analysis of stakeholder discourse. Through the collection of stakeholder interviews and the careful analysis of their content, this research offers a finer and more operational understanding of their perceptions and the ways in which these can be understood as a contributing factor of over-exposure.

\section{METHODS}

We chose a qualitative approach for this research, which, while not the dominant approach in risk perception studies, allows for the capture of statements that are not tainted by current results (i.e. pre-identified determinants looking for hypotheticodeductive confirmation). We adopted an exploratory stance, geared at identifying the proportions in which values, salience conditions and/or worldview influence stakeholders' perceptions.

Most perception studies on coastal flood risks are based on, or roughly inspired by, the psychometric paradigm (Slovic, 1987; 1992). This approach entails administering a quantitative questionaire to fairly large samples and establishing statistically significant correlations between social characteristics and perceptions. Rulleau et al. (2015), in their analysis of risk perceptions and flood risk on France's Languedoc-Roussillon seabord, use a questionnaire consisting of 158 questions first, reduced to 94 questions in the second phase. Their sample consisted of 881 respondents. Descriptive statistics of the responses are presented. Gonzalez-Riancho et al. (2015), in their analysis of risk perception and resilience in the German NorthSea coast, use stakeholder-based sampling in order to administer an on-line questionnaire. Their sample was limited to 16 respondents, yet their diversity allowed for capturing the range of interests present in the area. The size of the sample did not allow for formal statistical testing. Descriptive statistics of the responses are presented. Amos, Akpan, and Ogunjobi (2015) analyze household perception and vulnerability in a coastal area in Nigeria. They surveyed 101 households using a structured questionnaire, mixing quantitative and qualitative questions. Their analysis is centered on correlations between socioeconomic variables and perceptions of climate change impacts. They also assess whether perceived climate change is congruent 
with measured changes in local meteorological conditions. Adelekan and Asiyanbi (2016) analyze flood risk perception in Lagos. They collected data by administering a questionaire to a1000-respondent sample. They use the resulting data set to present key elements in terms of social and geographical characteristics as they relate to risk perception. Working on flash floods in a non-coastal setting, Bodoque et al. (2016) conduct an analysis of flash flood risk perceptions and their relationship with risk management. They used interviews of 254 adults to collect quantitative data. Through clustering analysis they infer some determinants of perception. Box et al. (2016), in their analysis of the 2011 Brisbane flood, use a mix of quantitative and qualitative approaches. They administered a quantitative questionnaire, resulting in the collection of 62 completed questionnaires (either collected on the spot or through online survey tools). They also met face to face with residents and asked qualitative questions.

In this paper we favor a qualitative approach to perception analysis. Considering the results currently available, it seems fundamental to further explore stakeholders' understandings of coastal flood risk. Qualitative approaches are recognized as allowing for such exploratory, inductive approaches to scientific enquiries. We used a grounded theory approach (Glaser and Strauss, 1967). "Grounded theory is one of the preferred methods and is among the most used in qualitative research. This method aims to develop a theory highlighting the process that allows individuals to assign meaning to what happens to them" (Couture, 2003).

This approach, which consists in developing a theoretical object from qualitative data, is currently used in fields as diverse as land-use planning analysis (Heacock and Hollander, 2011), health (McCreaddie and Payne, 2010), organizational analysis (Martin and Turner, 1986), applied ethics (Charmaz, 2011), psychology (Fassinger, 2005) and many others. Within risk studies, grounded theory was used recently for the analysis of risk governance (Touili et al., 2014) and for the analysis of paradigmatic tensions in coastal areas (Kane et al., 2014).

Fieldwork in a grounded theory approach combines description and abstraction. This involves conducting data collection and analysis through successive iteractions. The researcher moves between data collection and analysis. This implies that the various fieldwork sessions are separated by periods of analysis, which feed the next session of fieldwork in order to progressively build a corpus. The preliminary coding exercise (i.e. systematic interpretation and categorization of the data) allows for the identification of categories of meaning within the raw collected data. Then these categories are analyzed by identifying their properties. The next step is a conceptualization step based on relationships identified between categories. Preliminary classes are organized around the abstract concepts linking them. The properties of the concepts and relationships that exist with other concepts gradually increase the degree of abstraction. From this process one progressively builds the backbones of the theory that is constructed. This "theory" is the core of the results that are obtained.

In this study, fieldwork was conducted in the coastal city of Santander, Spain, in the Gironde estuary, France, and in the coastal city of Cesenatico, Italy. For each of these field settings, semi-structured interviews were conducted with key informants (see Tables 1 and 2). In total 29 key informants, representative of the diversity of interests present at the field sites, were interviewed.

Interviews were recorded and transcribed. In depth thematic coding (Aronson, 1994) (using two coders working in parallel, per corpus) was conducted on the Gironde and Santander corpuses with Atlas.ti (Lewins and Silver, 2007), using predefined and emerging thematic categories (see Table 3). An initial thematic analysis and categorization was conducted on these corpuses. Using the results of the initial thematic analysis and categorization, the Cesenaticao corpus was hand-coded. A second iteration of categorization was then conducted. The grounded theory was thereafter developed and stabilized.

\section{RESULTS}

In general terms, our analysis of the interview corpus shows that risk phenomenon relevance is established by the interviewees through a mix of expert-based knowledge and personal heuristics. Interviewees generally expressed that risks of highest pertinence are proxied by actual current investment in risk mitigation, and that investment decisions are driven by a mix of technocratic and economic considerations feeding political decisions, which are themselves mostly driven by normative claims. When pushing the analysis further, the relevance claims made were essentially presented as contingent on policy decisions, for which the key identified determinant was congruence with the normative claims expressed by stakeholders/voters.

In terms of evidence claims, our results allow for two levels of analysis regarding perceptions. These are associated with the three following questions: (a) What are, according to interviewees, the causes and effects of flooding? (b) What are the interviewees' bases for their beliefs regarding the causes and effects of flooding? (c) What are the interviewees' bases for understanding the probabilistic nature of floods?

In all study sites, interviewees stressed individual and collective behaviors as the main causes of vulnerability in past flood events. This is an extremely important result: meteorology, local topography and the like are not seen as the main causes of vulnerability, human behavior is. When attributing floods to behavior, interviewees stressed the impact of human activities on either flood management infrastructures (interfering with dykes, storm sewers, etc.) or with sensitive habitat (sand dunes mostly, and flood plains to a lesser extent).

Furthermore, interviewees stressed the fact that one mitigation strategy may have a distant effect on others: by raising grounds, increasing flood risk for non-raised rounds; breakwaters causing changes in sedimentary dynamics leading to erosion-based floods elsewhere; etc. When considering individual behaviors in the context of evidence claims, interviewees did mention overexposure, however only as framed as part of normative claims (see below).

At a more collective level, within evidence claims, the interviewees identify poorly designed policies in terms of governance processes, mostly poor land-use planning (e.g., real estate developments below sea level), administrative segmentation (e.g., different beach replenishing procedures in adjoining municipalities), lack of administrative coordination (e.g., building permits that are turned down at the local level then granted at a regional level), "absurd" engineering infrastructures 
Table 1. Interview framework.

Question
Looking the aerial coverage here can you identify places that are,
at risk of erosion, at risk of flooding.
We have explored together some key risk, flooding, erosion, in
your area. Now we would like to explore with you things that are
done in order to face those risks as they exist now and as they
could exist in the future. So a first dimension of this question is:
what is being done right now? A second question is about what
is planned for the future? A third, and important question for us
is what you believe should be done?
is planned for the future? A third, and
is what you believe should be done?

We are nearing the end of the interview. Regarding floods and erosion, are there things that you feel important that you would like to say. If you were to advise me, who are the two persons I should absolutely meet and why?
Associated Prompt

For this risk in this area: who are the persons/group that have a stake, and what is the nature of this stake. Why is this risk important/not important for you and for the key stakeholder that you have identified? What assets, natural or human made are at risk?

What about, current, future and recommended options in terms of engineering? What about, current, future and recommended options in terms of rehabilitating or conserving natural defense? What about land use planning as an option to minimize impacts or unwanted transformations (current, future, that you would recommend)? What about specific plans to help business recover after a flood (current, future, that you would recommend)? What about evacuation plans - emergency measures (current, future, that you would recommend)? What about insurance and compensation schemes (current, future, that you would recommend)? What about the governance of coastal areas with a focus on risk? What about specific measure in order to face post flood trauma? (e.g., flood gates that have never been functioning properly), and funding. Basically, when considering the causes of flood risk, participants identify a critical lack of risk governance, not a lack of knowledge.

When considering the knowledge bases that may be mobilized within evidence claims, participants stress the importance of individual and collective heuristics. Our analysis shows that the reliance on personal heuristics is unavoidable because, as interviewees stated: (a) available science shows problems of scale (i.e. available evidence concerns areas that are too small to be representative of flood events at the risk management scale); (b) the complexity of flood dynamics cannot possibly be captured by science as it is practiced; and (c) floods are multifactorial events, where human factors are very rarely recognized. In some instances, there are clear statements where interviewees criticized engineering options that are associated with science-based knowledge, thus disqualifying the latter for these interviewees. Finally, the probabilistic nature of floods is very seldom mentioned by the interviewees. The potential changes in flood probabilities, induced by climate change, are almost totally absent from the interviewees' statements.

The dominant normative narrative clearly expresses that the only acceptable way to envision coastal risk entails considering risk management options where the costs of flood risk and management are born collectively, even if the assets protected benefit a minority.

Furthermore, risk management strategies that are good collectively cannot be effectively implemented if they arm individual interests.
Analyzing this line of discourse shows that this "rule" suffers one exception: if the overexposed population chooses overexposure in order to reap benefits that are seen as "exaggerated" by the interviewees (e.g., high-value seafront real estate development, clearly below sea level), then no public money should be spent on managing the risk to which they are exposing themselves.

For all study sites the process of resolving conflicting normative claims is at the core of the process for envisioning flood risk. This is critical for the purpose of contributing to safer coasts. Any risk mitigation option will necessarily pass through a deliberation process regarding its acceptability, potentially regardless of the scientific quality of the knowledge that generated the mitigation option.

\section{DISCUSSION}

These results confirm the underlying hypothesis of the cultural theory of risk (Douglas and Widlawski,1983); interpretation and associated actions in the face of risk are dependant upon cultural norms that vary across cultures. The cultural theory of risk justifies the importance of culture when considering climate change impact and adaptation (Adger et al., 2013). Kahan et al. (2012) quantitatively tested a cultural theory hypothesis versus a knowledge gap hypothesis on climate change perception in the US. Their results unequivocally show that climate change perception is determined by one's peer group values and norms; knowledge and computational abilities show no influence. While in line with these, our results further specify this influence of culture. We show that culture not only determines our perception of risk, it determines our attitude regarding potential risk 
mitigation options. There is more than one cultural source of dissonance between the way experts frame risk and the way laypersons frame risk: the hazard may be the source as well as the response society chooses.

Table 2. Interviewee category.

\begin{tabular}{|c|c|c|c|}
\hline $\begin{array}{c}\text { Interviewee } \\
\text { Professional Category }\end{array}$ & Santander & Gironde & Cesenatico \\
\hline $\begin{array}{l}\text { River Basin } \\
\text { Authority Erosion } \\
\text { manager }\end{array}$ & $\mathrm{X}$ & $X$ & $X$ \\
\hline Land Use planner & $\mathrm{X}$ & & $\mathrm{X}$ \\
\hline Environmental planner & $\mathrm{X}$ & & \\
\hline $\begin{array}{l}\text { City Council employee } \\
\text { Regional level } \\
\text { employee of the } \\
\text { Ministry for } \\
\text { Environment }\end{array}$ & $\mathrm{X}$ & & $X$ \\
\hline Flood Risk manager & $\mathrm{X}$ & $\mathrm{X}$ & \\
\hline $\begin{array}{l}\text { Individual dealing with } \\
\text { social and sportive } \\
\text { activities in the } \\
\text { harbour }\end{array}$ & $\mathrm{X}$ & & $X$ \\
\hline Harbour administrator & $\mathrm{X}$ & $X$ & \\
\hline Harbour user & $\mathrm{X}$ & & \\
\hline $\begin{array}{l}\text { Coastal manager at the } \\
\text { national level }\end{array}$ & $X$ & & \\
\hline $\begin{array}{l}\text { Coastal manager at the } \\
\text { local or regional level }\end{array}$ & $\mathrm{X}$ & $\mathrm{X}$ & $\mathrm{X}$ \\
\hline $\begin{array}{l}\text { Industry owner } \\
\text { Representative of the } \\
\text { local Chamber of }\end{array}$ & $\mathrm{X}$ & & $\mathrm{X}$ \\
\hline $\begin{array}{l}\text { Commerce and } \\
\text { Industry, of a local } \\
\text { cooperative }\end{array}$ & $\mathrm{X}$ & & $\mathrm{X}$ \\
\hline Academic/Scientist & $X$ & $X$ & \\
\hline $\begin{array}{l}\text { Employee from an } \\
\text { NGO dealing with } \\
\text { public education }\end{array}$ & $\mathrm{X}$ & & \\
\hline $\begin{array}{l}\text { Employee from an } \\
\text { NGO dealing with } \\
\text { environmental } \\
\text { protection }\end{array}$ & $\mathrm{X}$ & $\mathrm{X}$ & \\
\hline
\end{tabular}

Our results extend past our original working hypothesis regarding overexposure. While biased perception may be a source of overexposure, the mechanics of overexposure are much more complex. Perception bias influences attitudes toward potential corrective actions. In their analysis of flood risk in Lagos, Adelekan and Asiyanbi (2016) underline that unpreparation for flooding, overexposure, and biased flood risk perception are intimately connected. They argue that knowledge gaps may be an explanatory factor. Our results go beyond this and show that overexposure may, in some situations, be explained by material constraints and associated salience along with cultural norms.
Similarly, Amos, Akpan, and Ogunjobi (2015) demonstrate empirically that while members of coastal communities in Akwa Ibom State, Nigeria, do perceive climate change, their vulnerability remains high and can be attributed to their material and cultural constraints.

As we argue elsewhere (Kane et al., 2014), our results also indicate that risk communication should not limit itself to the communication of information on the nature of the hazard (e.g., intensity and associated probabilities). Lozoya et al. (2015) also propose a communication scheme geared at going beyond the knowledge gap hypothesis when envisioning differing risk perceptions. Risk communication, while occurring at all stages of risk governance (Renn, 2008), must pertain to all dimensions of risk, including risk mitigation options and their interconnectedness with local cultural characteristics, values and norms (see Touili et al., 2014). This resonates strongly with the results of Gonzalez-Riancho et al. (2015) following their analysis of risk perception and resilience on the German North Sea Coast. They demonstrate that, while seemingly underestimating flood risks, the majority of respondents argued in favour of more participatory and multi-stakeholder approaches to risk management throughout the risk governance cycle. The centrality of local norms and values, and the importance of integrating exposed populations in all phases of risk governance, resonates also with the results obtained by Box et al. (2016). Analyzing shared responsability and social responsibility during the 2011 Bribane floods, Box et al. (2016) demonstrate the need for residents to understand and "perceive" all dimensions of flood risk - from hazard up to recovery. In the same vein, Rulleau et al. (2015) show that information on crisis management itself is a critical part of the knowledge that needs to be shared. These results combined with ours argue strongly in favour of widelydefined negotiation spaces allowing all stakeholders to share their values, material constraints, and knowledge as they pertain to all the elements of risk governance.

Our results also indicate that the interplay between vulnerability and perceptions may leave specific roles for values and material constraints in the perception of flood risk, extending beyond the mere issue of a knowledge gap. Very early in the literature pertaining to flooding and social vulnerability, access to knowledge is identified as a potential driver of social vulnerability. Cutter, in a series of seminal papers, identifies "social fabric" as a central determinant of vulnerability (Cutter, Boruff, and Shirley, 2003; Cutter, Mitchell, and Scott, 2000). "Lack of access to knowledge" as well as "certain beliefs or customs" (Cutter, Mitchell, and Scott, 2000) are initially identified as manifestations of the social fabric that are central to vulnerability. Later, "perception" is explicitly mentioned in the conceptual model (Cutter, Boruff, and Shirley, 2003); yet its empirical declination is not very explicit. Education is mentioned as a proxy for earning abilities - indicating that knowledge gaps and material constraints may be intertwined. More recently, Zou and Wei (2010) conducted a meta-analysis of the literature on coastal vulnerability in Southeast Asia. They find "increasing hazard awareness and knowledge is one of the most preferred recommendations" to reduce vulnerability. This points to the prevalence of the knowledge gap hypothesis in vulnerability literature. Nevertheless, Zou and Wei's meta-analysis allows for 
Table 3. Coding categories.

\begin{tabular}{|c|c|c|}
\hline Origin of the Codes Used & Code Name & Summary Description of the Coded Contents \\
\hline \multirow[t]{3}{*}{$\begin{array}{l}\text { Predefined codes pertaining to risk perception } \\
\text { via an integrative framewok (see text) }\end{array}$} & Relevance Claim & $\begin{array}{l}\text { Quotes where the interviewee states what is a } \\
\text { phenomenon worth attention. }\end{array}$ \\
\hline & Evidence claim & $\begin{array}{l}\text { Quotes where the interviewee establishes } \\
\text { causal linkages related to coastal flooding. }\end{array}$ \\
\hline & Normative claim & $\begin{array}{l}\text { Quotes where the interviewee states what is } \\
\text { good, acceptable and tolerable regarding } \\
\text { coastal flooding risk management options. }\end{array}$ \\
\hline \multirow[t]{3}{*}{ Emerging categories } & Uncertainty & $\begin{array}{l}\text { Quotes where the interviewee states the role of } \\
\text { uncertainty. }\end{array}$ \\
\hline & Future & $\begin{array}{l}\text { Quotes where the interviewee states his beliefs } \\
\text { about future states of the coastal flooding risk } \\
\text { related issues. }\end{array}$ \\
\hline & Options & $\begin{array}{l}\text { Quotes where the interviewee states his beliefs } \\
\text { about coastal flooding risk mitigation options. }\end{array}$ \\
\hline
\end{tabular}

the identification of the vulnerability-driver category "perception and behaviour" containing "religious perception", "perceptions from past experience", and cultural norms. This is compatible with our results, which offer a more precise specification of these influences. We have observed that action against risk is contigent upon its congruence with cultural norms and key local values.

\section{CONCLUSIONS}

The results presented here show that in these case studies, there is very little consideration of science-based knowledge in the public's and stakeholders' attitudes toward and perceptions of flood risk. On the one hand, the knowledge used to frame risk belongs to the world of individual and collective experience. On the other, values and norms occupy most of the cognitive space when framing risk. The risk perception analysis presented here sheds light on the path to safer coasts. From the analysis conducted, it appears first and foremost that stakeholders' perceptions of flood risk are driven by considerations that have very little to do with the hazards and associated probabilities outlined by the scientific community. For local stakeholders, risk management is mostly associated with the ability to make decisions that are compatible with the core values of the affected communities. Consequently, any initiative to reduce risk that is not co-constructed with the affected communities will most likely not be implemented for reasons that have nothing to do with the quality of the knowledge base that is mobilized. What is even more challenging is that in some cases this heuristic leads risk stakeholders to a genuine mistrust of science-based or engineering-based approaches. These results show that for local communities, if a solution is to be found for overexposure to flood risk, it lies in better risk governance rooted in an explicit taking into account of the values expressed by potential flood victims. In more general terms, our results demonstrate that, if science-based knowledge is to have its place in climate change and coastal risk governance, it is of critical importance that its production takes place through processes that allow for continual interactions with those at risk and an understanding of their values. If science-based knowledge is to be a solution to the problem of (mis) perception, then particular care will have to be given to the way science is practiced.

\section{ACKNOWLEDGMENTS}

The support of the European Commission through FP7.20091, Contract 244104 - THESEUS ("Innovative technologies for safer European coasts in a changing climate"), is gratefully acknowledged.

\section{LITERATURE CITED}

Adelekan, I.O. and Asiyanbi, A.P., 2016. Flood risk perception in flood-affected communities in Lagos, Nigeria. Natural Hazards, 80(1), 445-469.

Adger, W.N.; Barnett, J.; Brown, K.; Marshall, N., and O'Brien, K., 2013. Cultural dimensions of climate change impacts and adaptation. Nature Climate Change, 3(2), 112-117.

Amos, E.; Akpan, U., and Ogunjobi, K., 2015. Households' perception and livelihood vulnerability to climate change in a coastal area of Akwa Ibom State, Nigeria. Environment, Development and Sustainability, 17(4), 887-908.

Aronson, J., 1994. A pragmatic view of thematic analysis. The Qualitative Report, 2(1).

Birkmann, J., 2007. Risk and vulnerability indicators at different scales: Applicability, usefulness and policy implications. Environmental Hazards, 7(1), 20-31.

Birkmann, J.; Cardona, O.; Carreño, M.; Barbat, A.; Pelling, M.; Schneiderbauer, S.; Kienberger, S.; Keiler, M.; Alexander, D., and Zeil, P., 2013. Framing vulnerability, risk and societal responses: The MOVE framework. Natural Hazards, 67(2), 193-211.

Bodoque, J.; Amérigo, M.; Díez-Herrero, A.; García, J.; Cortés, B.; Ballesteros-Cánovas, J., and Olcina, J., 2016. Improvement of resilience of urban areas by integrating social perception in flash-flood risk management. Journal of Hydrology, 54(1), 665-676.

Box, P.; Bird, D.; Haynes, K., and King, D., 2016. Shared responsibility and social vulnerability in the 2011 Brisbane flood. Natural Hazards, 81(3), 1549-1568.

Burby, R.J., 2006. Hurricane Katrina and the paradoxes of government disaster policy: Bringing about wise governmental decisions for hazardous areas. The ANNALS of the American Academy of Political and Social Science, 604(1), 171-191.

Charmaz, K., 2011. Grounded theory methods in social justice research. In: Denzin, N.K. and Lincoln, Y.S. (eds.), The SAGE Handbook of Qualitative Research. Thousand Oaks: SAGE, pp. 359-380. 
Couture, M., 2003. La recherche qualitative: Introduction à la théorisation ancrée. Interactions, 7(2), 127-133.

Cowell, P.J.; Thom, B.G.; Jones, R.A.; Everts, C.H., and Simanovic, D., 2006. Management of uncertainty in predicting climate-change: Impacts on beaches. Journal of Coastal Research, 22(1), 232-245.

Cutter, S.L.; Boruff, B.J., and Shirley, W.L., 2003. Social vulnerability to environmental hazards. Social Science Quarterly, 84(2), 242-261.

Cutter, S.L.; Mitchell, J.T., and Scott, M.S., 2000. Revealing the vulnerability of people and places: A case study of Georgetown County, South Carolina. Annals of the Association of American Geographers, 90(4), 713-737.

Douglas, M. and Wildavsky, A., 1983. Risk and Culture: An Essay on the Selection of Technological and Environmental Dangers. Berkeley: University of California Press, 221p.

Eisenman, D.P.; Cordasco, K.M.; Asch, S.; Golden, J.F., and Glik, D., 2007. Disaster planning and risk communication with vulnerable communities: Lessons from Hurricane Katrina. American Journal of Public Health, 97(supplement_1), s109s115.

Fassinger, R.E., 2005. Paradigms, praxis, problems, and promise: Grounded theory in counseling psychology research. Journal of Counseling Psychology, 52(2), 156-166.

Glaser, B.G. and Straus, A.L., 1967. The Discovery of Grounded Theory. Chicago: Aldine, 265p.

González-Riancho, P.; Gerkensmeier, B.; Ratter, B.M.; González, M., and Medina, R., 2015. Storm surge risk perception and resilience: A pilot study in the German North Sea coast. Ocean \& Coastal Management, 112, 44-60.

Hansen, J.; Sato, M., and Ruedy, R., 2012. Perception of climate change. Proceedings of the National Academy of Sciences, 109(37), E2415-E2423.

Heacock, E. and Hollander, J., 2011. A grounded theory approach to development suitability analysis. Landscape and Urban Planning, 100(1-2), 109-116.

Kahan, D.M.; Peters, E.; Wittlin, M.; Slovic, P.; Larrimore Ouellette, L.; Braman, D., and Mandel, G., 2012. The polarizing impact of science literacy and numeracy on perceived climate change risks. Nature Climate Change, 2(10), 732-735.

Kane, I.O.; Vanderlinden, J.-P.; Baztan, J.; Touili, N., and Claus, S., 2014. Communicating risk through a DSS: A coastal risk centred empirical analysis. Coastal Engineering, 87, 240-248.

Lee, T.M.; Markowitz, E.M.; Howe, P.D.; Ko, C.-Y., and Leiserowitz, A.A., 2015. Predictors of public climate change awareness and risk perception around the world. Nature Climate Change, 5(11), 1014-1020.

Leiserowitz, A., 2006. Climate change risk perception and policy preferences: The role of affect, imagery, and values. Climatic Change, 77(1-2), 45-72.

Lewins, A. and Silver, C., 2007. Using Software in Qualitative Research: A Step by Step Guide. London: SAGE Publications, $384 \mathrm{p}$.

Lozoya, J.; Conde, D.; Asmus, M.; Polette, M.; Píriz, C.; Martins, F.; de Álava, D.; Marenzi, R.; Nin, M., and Anello, L., 2015. Linking social perception and risk analysis to assess vulnerability of coastal socio-ecological systems to climate change in Atlantic South America. In: Filho, W.L. (ed.), Handbook of Climate Change Adaptation. Berlin, Germany: Springer, pp. 373-399.

Lujala, P.; Lein, H., and Rød, J.K., 2015. Climate change, natural hazards, and risk perception: The role of proximity and personal experience. Local Environment, 20(4), 489-509.

Martin, P.Y. and Turner, B.A., 1986. Grounded theory and organizational research. Journal of Applied Behavioral Science, 22(2), 1441-1157.

McCreaddie, M. and Payne, S., 2010. Evolving grounded theory methodology: Towards a discursive approach. International Journal of Nursing Studies, 47(6), 781-793.

Renn, O., 2008. Risk Governance: Coping with Uncertainty in a Complex World. London: Earthscan, 455p.

Rufat, S.; Tate, E.; Burton, C.G., and Maroof, A.S., 2015. Social vulnerability to floods: Review of case studies and implications for measurement. International Journal of Disaster Risk Reduction, 14(Part 4), 470-486.

Rulleau, B.; Rey-Valette, H.; Flanquart, H.; Hellequin, A.-P., and Meur-Férec, C., 2015. Perception des risques de submersion marine et capacité d'adaptation des populations littorales. «On a eu la guerre, ils auront les inondations!». VertigO-la Revue Électronique en Sciences de l'Environnement, Hors-série 21.

Schneider, S.K., 2005. Administrative breakdowns in the governmental response to Hurricane Katrina. Public Administration Review, 65(5), 515-516.

Semenza, J.C.; Hall, D.E.; Wilson, D.J.; Bontempo, B.D.; Sailor, D.J., and George, L.A., 2008. Public perception of climate change: Voluntary mitigation and barriers to behavior change American Journal of Preventive Medicine, 35(5), 479-487.

Siegrist, M. and Gutscher, H., 2006. Flooding risks: A comparison of lay people's perceptions and expert's assessments in Switzerland. Risk Analysis, 26(4), 971-979.

Slovic, P., 1987. Perception of risk. Science, 236(4799), 280-285.

Slovic, P., 1992. Perception of risk: Reflexions on the psychometric paradigm. In: Krimsky, S. and Golding, D. (eds.), Social Theories of Risk. Westport, CT: Praeger, pp. 117152.

Touili, N.; Baztan, J.; Vanderlinden, J.-P.; Kane, I.O.; DiazSimal, P., and Pietrantoni, L., 2014. Public perception of engineering-based coastal flooding and erosion risk mitigation options: Lessons from three European coastal settings. Coastal Engineering, 87, 205-209.

Whitmarsh, L., 2008. Are flood victims more concerned about climate change than other people? The role of direct experience in risk perception and behavioural response. Journal of Risk Research, 11(3), 351-374.

Zanuttigh, B., 2011. Coastal flood protection: What perspective in a changing climate? The THESEUS approach. Environmental Science \& Policy, 14(7), 845-863.

Zou, L.L. and Wei, T.-M., 2010. Driving factors for social vulnerability to coastal hazards in Southeast Asia: Results from the meta-analysis. Natural Hazards, 54, 901-920. 